\title{
ANALISA CAKUPAN AREA DAN KAPASITAS PENGGUNA PADA PENGUKURAN KUAT SINYAL UNTUK JARINGAN GSM 900 MHZ
}

\author{
Taqwa Nur ${ }^{1}$, Syahfrizal Tachfulloh ${ }^{2}$ \\ ${ }^{1,2}$ Teknik Elektro, Universitas Borneo Tarakan, Tarakan, Kalimantan Utara, Indonesia \\ 1taqwa_nur92@yahoo.co.id \\ 2rizalubtegmail.com
}

\begin{abstract}
Global Syistem and Mobile Communications or GSM short ordinary character is a digital technology, has details of modulation and architecture of the network and service level at a frequency of $900 \mathrm{MHz}, 1800 \mathrm{MHz}$, and 1900 $\mathrm{MHz}$ (Cellular Frequency in Indonesia, Pacific WaveIndonesia, 2007). PT. Telkomsel as the first GSM mobile telecommunications operator in Indonesia, to date total cellular subscribers of Telkomsel is the largest in Indonesia. Along the rapid increase of mobile service users, the demand for increased capacity of mobile service users is also increasing, especially in urban areas. It is necessary for planning the coverage area and the calculation of the correct capacity in order to improve services to users of mobile services.
\end{abstract}

In this study the authors used three methods, namely, Cost-231, Free Space, and Stanford Univercity Interim (SUI). The third method is used as the calculation of path loss on the network. Where the path loss calculation results in all three methods are used as a reference in determining the coverage area and capacity planning of the GSM network.

Results of the calculations show that the three methods, cost-231 is the method most suitable for use in the town of Tarakan, it is shown from the calculation RMSE (Root Mean Square Error) in which the obtained value of loss is the smallest on the cost-231 is $8.138 \mathrm{~dB}$ whereas free space 24.967 $d B$ and SUI $43.914 d B$.

Keywords-GSM $900 \mathrm{MHz}$, Path Loss, Coverage Area and User Capacity.

Intisari- Global System and Mobile Communication atau biasa singkat GSM merupakan sebuah teknologi bersifat digital, memiliki rincian modulasi dan arsitektur ditingkat jaringan dan layanan pada frekuensi $900 \mathrm{MHz}$, $1800 \mathrm{MHz}$, dan $1900 \mathrm{MHz}$ (Cellular Frequency in Indonesia, Pasific Wave-Indonesia, 2007). PT. Telkomsel sebagai operator telekomunikasi seluler GSM pertama di Indonesia, sampai saat ini total pelanggan seluler Telkomsel masih yang terbesar di Indonesia. Seiring bertambah pesatnya pengguna layanan seluler, permintaan peningkatan kapasitas pengguna layanan seluler juga bertambah, khususnya pada area perkotaan. Untuk itu diperlukan perencanaan cakupan area dan perhitungan kapasitas yang benar agar dapat meningkatkan pelayanan kepada para pengguna layanan seluler.

Pada penelitian ini penulis menggunakan tiga metode yaitu, Cost-231, Free Space, dan Stanford University Interim (SUI). Ketiga metode ini digunakan sebagai perhitungan path loss pada jaringan. Dimana hasil perhitungan path loss pada ketiga metode tersebut dijadikan acuan dalam menentukan perencanaan cakupan area dan kapasitas pengguna jaringan GSM.
Hasil pada perhitungan menunjukkan bahwa dari ketiga metode, cost-231 merupakan metode yang paling cocok digunakan di kota Tarakan, hal ini ditunjukkan dari perhitungan RMSE (Root Mean Square Error) dimana didapatkan nilai loss paling kecil pada cost-231 yaitu 8,138 dB sedangkan pada free space $24,967 \mathrm{~dB}$ dan SUI 43,914 dB.

Kata Kunci- GSM 900 MHz, Path Loss, Cakupan area dan Kapasitas Pengguna.

\section{PENDAhuluan}

Salah satu sistem telekomunikasi yang banyak digunakan saat ini adalah sistem telekomunikasi pada jaringan GSM. Global System and Mobile Communication atau biasa singkat GSM merupakan sebuah teknologi bersifat digital, memiliki rincian modulasi dan arsitektur ditingkat jaringan dan layanan pada frekuensi $900 \mathrm{MHz}, 1800 \mathrm{MHz}$, dan $1900 \mathrm{MHz}$ (Cellular Frequency in Indonesia, Pacific Wave-Indonesia, 2007).

PT. Telkomsel sebagai operator telekomunikasi seluler GSM pertama di Indonesia, sampai saat ini total pelanggan seluler Telkomsel masih yang terbesar di Indonesia, yakni sekitar 125 juta (Kenny Pratama Putra, 2014). Banyaknya pelanggan seluler Telkomsel menujukkan pengguna sistem komunikasi GSM berkembang dengan pesat, seiring bertambah pesatnya pengguna layanan seluler, permintaan peningkatan kapasitas pengguna layanan seluler juga bertambah, khususnya pada area perkotaan. Untuk itu diperlukan perencanaan cakupan area dan perhitungan kapasitas yang benar agar dapat meningkatkan pelayanan kepada para pengguna layanan seluler.

Pada penelitian ini penulis akan menentukan cakupan area dan kapasitas dengan menggunakan metode Free Space, Cost-231, dan Stanford University Interim (SUI). Dari beberapa metode ini nantinya masing-masing akan menghasilkan nilai path loss, dimana dari hasil tersebut akan dijadikan acuan untuk melakukan perhitungan dan analisa pada cakupan area dan kapasitas pengguna pada jaringan GSM.

\section{METODE PENELITIAN}

Tempat pelaksanaan penelitian dilakukan di Fakultas Teknik Universitas Borneo Tarakan, dengan tahapantahapan penelitian sebagai berikut : 
1. Data yang digunakan dalam penelitian ini merupakan data sekunder yang diambil dari penelitian terdahulu. Dimana data tersebut didapat dari PT. Telekomunikasi Selular Regional Kalimantan Cabang Tarakan. Adapun data yang dibutuhkan antara lain nilai loss propagasi pada daerah sub urban, nilai Frekuensi Carrier, Tinggi BTS, Tinggi antena mobile station, dan jarak Tx - Rx.

2. Mendapatkan nilai EIRP.

3. Melakukan perhitungan path loss.

4. Setelah melakukan perhitungan path loss, kemudian akan menentukan dan menampilkan grafik dari masing-masing pemodelan.

5. Menghitung RMSE (Root Mean Square Error). Tujuan menghitung RSME adalah untuk mencari koefisien sehingga memperkecil adanya kesalahan kuadrat rata-rata. RMSE dapat dinyatakan sebagai berikut:

$$
\text { RMSE }=\sqrt{\sum\left(P_{m}-P_{\gamma}\right)^{2}} /(N-1)
$$

Dimana:

$$
\begin{aligned}
& P_{m}=\text { Pengukuran Path Loss } \\
& P_{r}=\text { Perkiraan Path Loss } \\
& N=\text { Jumlah Titik Data yang Diukur }
\end{aligned}
$$

6. Selanjutnya adalah melakukan perhitungan cakupan daerah dan kapsitas pada jaringan GSM dari masingmasing pemodelan yang dipakai, setelah itu menampilkan grafik.

7. Langkah terakhir yang akan dilakukan adalah menganalisa apa yang telah didapat dari hasil perhitungan dan hasil dari grafik yang akan ditampilkan. Dan kemudian menentukan pemodelan yang terbaik pada penelitian ini.

\section{A. Arsitektur GSM}

Karakteristiknya yang open standard interface (memungkinkan vendor-vendor untuk ikut mengembangkan instrumennya pada sisi jaringan network), jangkauan luas (roaming access), interoperabilitas serta kemudahan penggunaan SIM card pada handset yang berbeda tanpa mengurangi fungsi konektivitasnya ini merupakan beberapa faktor yang menyebabkan perkembangan jaringan GSM sedemikian pesat pada kurun waktu beberapa tahun terakhir [2].

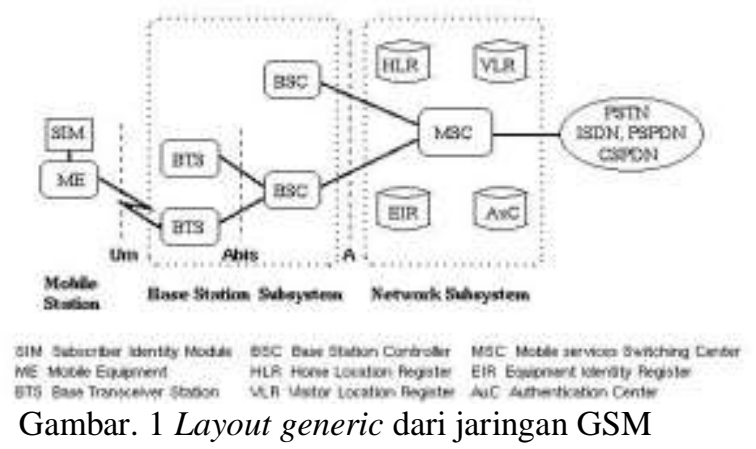

Arsitektur jaringan GSM terdiri dari 3 komponen utama yaitu:

\section{Mobile Station}

2. Base Station Subsystem (BSS)

3. Network Sub System (NSS)

\section{B. Path Loss}

Path loss adalah suatu metode yang digunakan untuk mengukur suatu loss yang disebabkan oleh cuaca, kontur tanah dan lain-lain, agar tidak menggangu pemancaran antar dua buah antena yang saling berhubungan. Nilai path loss menunjukkan level sinyal yang melemah yang disebabkan oleh propagasi free space seperti refleksi, difraksi, dan scattering. Path loss sangat penting dalam perhitungan link budget, ukuran cell, ataupun perencanaan frekuensi. Faktor-faktor yang mempengaruhi nilai level daya dan path loss adalah jarak pengukuran antara Tx dan $\mathrm{Rx}$, tinggi antena ( $\mathrm{Tx}$ dan $\mathrm{Rx}$ ), serta jenis area pengukuran [4].

Persamaan untuk menghitung path loss :

$P_{L}=E I R P-P_{T}$

Dimana :

$R_{\mathrm{L}}=$ Path Loss $(\mathrm{dB})$

EIRP $=$ Effective isotropic radiated power

$P_{F}=$ Received Power $(\mathrm{dB})$

\section{EIRP (Effective Isotropic Radiative Power)}

EIRP adalah total energi yang di keluarkan oleh sebuah transmitter dan antena. Saat sebuah transmitter mengirim energinya ke antena untuk dipancarkan, sebuah kabel mungkin ada diantaranya. Beberapa pengurangan besar energi tersebut akan terjadi di dalam kabel. Untuk mengimbangi hal tersebut, sebuah antena menambahkan power/Gain, dengan demikian power bertambah. Jumlah penambahan power tersebut tergantung tipe antena yang digunakan. FCC (The Federal Communications Commission) dan ETSI (The European Telecommunications Standards Institute) mengatur besar power yang bisa dipancarkan oleh antena. EIRP inilah yang digunakan untuk memperkirakan area layanan sebuah alat jaringan [3].

\section{Rumus dari EIRP :}

EIRP $=$ Power Output Transmitter (AP) - Cable loss + Antena Gain

\section{Model Propagasi}

Penggunaan model-model propagasi sangat bermaanfaat untuk menentukan berapa banyak Cell Site (BTS) yang diperlukan untuk memenuhi cakupan suatu jaringan. Model-model propagasi membantu menentukan dimana BTS-BTS harus diletakkan untuk memperoleh posisi yang optimal dalam jaringan. Performansi jaringan dipengaruhi oleh model propagasi yang dipilih, karena model tersebut digunakan untuk prediksi interferensi [5].

Adapun model propagasi yang digunakan dalam penelitian ini adalah free Space (FSPL), Stanford University Interim (SUI), dan Cost-231. 
1. Free Space (FSPL)

FSPL adalah penurunan kekuatan sinyal yang dihadapi oleh gelombang elektromagnetik, yang dihasilkan dari line-of-sight melalui ruang bebas. Dalam konteks ini, line-of-sight bebas dari penghalang dan hambatan, baik secara alami maupun buatan manusia yang mungkin menyebabkan refleksi atau difraksi. FSPL dinyatakan dalam satuan $\mathrm{dB}$, sebagai berikut :

$F S P L(d B)=20 \log _{10}(d)+20 \log _{10}(f)+32,45$

Dimana :

$f=$ Frekuensi $(\mathrm{MHz})$

$d=\operatorname{Jarak}(\mathrm{km})$

\section{Stanford University Interim (SUI)}

Standar yang diusulkan untuk pita frekuensi dibawah $11 \mathrm{GHz}$ berisi model saluran yang dikembangkan di Stanford University. Model SUI diklasifikasikan menjadi 3 jenis medan, yaitu A, B, dan C. Tipe A dikaitkan dengan path loss maksimum dan cocok untuk medan berbukit. Tipe $\mathrm{C}$ dikaitkan dengan path loss minimum dan cocok untuk medan datar dengan kepadatan pohon. Tipe $\mathrm{B}$ ditandai dengan sebagian besar medan datar dengan kepadatan pohon atau medan berbukit dengan kepadatan pohon. Persamaan dasar path loss dengan faktor koreksi :

$P_{L}=A+10 \gamma \log _{10} d / d_{0}+x f+x_{h}+s_{y} d>d_{0}$

Dimana $d$ adalah jarak dalam meter antara penerima dan (BS), $\mathrm{d}_{0}=100 \mathrm{~m}$ dan $\mathrm{s}$ adalah log faktor yang biasanya memberikan bayangan memudar akibat dari pohon dan mengacaukan yang lainnya; nilainya bervariasi antara 8.2 dan $10.6 \mathrm{~dB}$, parameter lainnya yang didefinisikan sebagai berikut (Rekawt S. Hassan, 2014) :

$A=20 \log _{10}\left(4 \pi d_{0} / \lambda\right)$
$\gamma=a-b h_{b}+c / h_{b}$

\section{Dimana}

$h_{b}=$ Base Station (BS) ketinggian diatas tanah (harus antara 10 dan $80 \mathrm{~m}$ ).

$\gamma=$ Path Loss eksponen.

Nilai-nilai yang digunakan untuk konstanta A, B, dan $\mathrm{C}$ terdapat pada tabel I berikut.

Tabel I

Nilai konstanta yang digunakan pada medan A, B, dan C

\begin{tabular}{|l|l|l|l|}
\hline \multicolumn{1}{|c|}{ Parameter } & Medan A & Medan B & Medan C \\
\hline A & 4,6000 & 4,0000 & 3,6000 \\
\hline B (m-1) & 0,0075 & 0,0065 & 0,0050 \\
\hline C (m) & 12,6000 & 17,1000 & 20,0000 \\
\hline
\end{tabular}

Untuk tipe medan path loss eksponen ditentukan oleh $h_{b}$. Faktor koreksi model untuk operasi frekuensi dan tinggi antenna penerima adalah :

$x f=6,0 \log _{10}(f / 2000)$;

$x_{\mathrm{h}}=-10,8 \log _{10}\left(h_{F} / 2000\right) ;$ untuk jenis medan a dan b (9)

$X_{h}=-20 \log _{10}\left(h_{F} / 2000\right) ;$ untuk jenis medan c
Dimana $f(\mathrm{MHz})$ adalah frekuensi dan $h_{r}(\mathrm{~m})$ adalah tinggi antena penerima di atas tanah. Model SUI digunakan untuk memprediksi path loss pada tiga lingkungan yang yaitu pedesaan, pinggiran kota dan perkotaan.

\section{Cost-231}

Cost-231 dirancang untuk digunakan dalam rentan frekuensi $1500 \mathrm{MHz}$ sampai $2 \mathrm{GHz}$. Model ini menggabungkan faktor koreksi untuk perkotaan, pinggiran kota dan lingkungan pedesaan. Persamaan dasar path loss dalam $\mathrm{dB}$ dinyatakan sebagai berikut :

$\mathrm{P}_{\mathrm{L}}=46,3+33,9 \log _{10}(f)-13,82 \log _{10}\left(h_{b}\right)-a h_{r}+(44,9$ $-6,55 \log _{10}\left(h_{b}\right) \log _{10} d+C$

Parameter $\mathrm{C}=0 \mathrm{~dB}$ untuk perkotaan dan lingkungan pinggiran kota. Sedangkan $\mathrm{C}=3 \mathrm{~dB}$ untuk lingkungan perkotaan. Untuk semua parameter adalah, $h_{b}(30-200 \mathrm{~m})$ dan $h_{r}(1-10 \mathrm{~m}) \quad$ [6],[7].

\section{HASIL DAN PEMBAHASAN}

A. Simulasi Pemodelan

Tabel II

Parameter yang digunakan pada simulasi

\begin{tabular}{|l|l|}
\hline \multicolumn{1}{|c|}{ Parameter } & \multicolumn{1}{c|}{ Value } \\
\hline \multirow{4}{*}{ Frekuensi } & (BTS 1) 946,2 MHz \\
\cline { 2 - 2 } & (BTS 2) 945,8 MHz \\
\cline { 2 - 2 } & (BTS 3) 946,8 MHz \\
\hline Tinggi Antena & $30 \mathrm{~m}$ \\
\hline Tinggi Penerima & $1,5 \mathrm{~m}$ \\
\hline Tenaga transmisi & $20 \mathrm{w}$ \\
\hline Rugi-rugi kabel & $1,65 \mathrm{dBm}$ \\
\hline Gain Antena & $18 \mathrm{dBm}$ \\
\hline EIRP & $43 \mathrm{dBm}$ \\
\hline Chip Rate & $3,84 \mathrm{Mbps}$ \\
\hline Shadow fading loss & $8,7 \mathrm{Db}$ \\
\hline
\end{tabular}

B. Hasil Perhitungan

Dari parameter-parameter yang telah didapat akan dilalakukan perhitungan path loss, dimana pada perhitungan path loss ini menggunakan tiga metode yaitu, free space, SUI, dan cost-231.

1. Perhitungan Path Loss dengan metode free space Contoh perhitungan untuk Free Space :

$$
\text { Dengan } \quad \begin{aligned}
f & =946,2 \mathrm{MHz} \\
d & =0,10 \mathrm{~km}
\end{aligned}
$$

Penyelesaian :

$$
\begin{aligned}
& 20 \log _{10}(d)+20 \log _{10}(f)+32,45 \\
= & 20 \log (0,10)+20 \log (946,2)+32,45 \\
= & 71,97 \mathrm{~dB}
\end{aligned}
$$


Tabel III

Hasil Perhitungan Path Loss Menggunakan Pemodelan Free Space

\begin{tabular}{|c|c|c|c|}
\hline \multirow{2}{*}{$\mathrm{d}(\mathrm{km})$} & \multicolumn{3}{|c|}{ Free Space Path Loss $(\mathrm{dB})$} \\
\cline { 2 - 4 } & $\begin{array}{c}\text { BTS 1 } \\
(946,2 \mathrm{MHz})\end{array}$ & $\begin{array}{c}\text { BTS 2 } \\
(945,8 \mathrm{MHz})\end{array}$ & $\begin{array}{c}\text { BTS 3 } \\
(946,8 \mathrm{MHz})\end{array}$ \\
\hline 0,10 & 71,97 & 71,97 & 71,98 \\
\hline 0,30 & 81,51 & 81,51 & 81,52 \\
\hline 0,50 & 85,95 & 85,95 & 85,95 \\
\hline 0,70 & 88,87 & 88,87 & 88,88 \\
\hline 0,90 & 91,05 & 91,05 & 91,06 \\
\hline 1,10 & 92,80 & 92,79 & 92,80 \\
\hline 1,30 & 94,25 & 94,24 & 94,25 \\
\hline 1,50 & 95,49 & 95,49 & 95,50 \\
\hline 1,70 & 96,58 & 96,57 & 96,58 \\
\hline 1,90 & 97,54 & 97,54 & 97,55 \\
\hline 2,10 & 98,41 & 98,42 & 98,42 \\
\hline 2,30 & 99,20 & 99,20 & 99,21 \\
\hline 2,50 & 99,93 & 99,92 & 99,93 \\
\hline
\end{tabular}

Tabel III merupakan hasil perhitungan path loss menggunakan metode free space dimana didapatkan nilainilai path loss dari BTS 1 - BTS 3 dari jarak 10 meter sampai dengan $2,5 \mathrm{~km}$.

2. Perhitungan Path Loss dengan Metode SUI

Contoh perhitungan path loss untuk pemodelan SUI :

Dengan $f=946,2 \mathrm{MHz}$

$h_{\text {bs }}=30$ Meter

$h_{\text {ms }}=1,5$ Meter

$d_{0} \quad=100$ Meter

$\lambda \quad=0,317$ Meter

$A_{\text {SUI }}=20 \log _{10}\left(4 \pi d_{0} / \lambda\right)$

$\gamma \quad=a-b h_{b}+c / h_{b}$

xf $\quad=6,0 \log _{10}(f / 2000)$

$X_{h} \quad=-10,8 \log _{10}\left(h_{m s} / 2000\right)$

Penyelesaian

$$
\begin{aligned}
P_{L}= & A+\frac{10 \gamma \log _{10} d}{d_{0}}+x f+X h+s_{v} d>d_{0} \\
& =71_{x} 956+\left(10 \times 4,375 \log +\left(0,10 \times \frac{1000}{100}\right)-1,95+\right. \\
& 33_{x} 749+8,2
\end{aligned}
$$$$
=111_{x} 96 \mathrm{~dB}
$$

Tabel IV

Hasil perhitungan path loss menggunakan pemodelan SUI

\begin{tabular}{|c|c|c|c|}
\hline \multirow{2}{*}{$\mathrm{d}(\mathrm{km})$} & \multicolumn{3}{|c|}{ SUI $(\mathrm{dB})$} \\
\cline { 2 - 4 } & $\begin{array}{c}\text { BTS 1 } \\
(946,2 \mathrm{MHz})\end{array}$ & $\begin{array}{c}\text { BTS 2 } \\
(945,8 \mathrm{MHz})\end{array}$ & $\begin{array}{c}\text { BTS 3 } \\
(946,8 \mathrm{MHz})\end{array}$ \\
\hline 0,10 & 111.96 & 111,96 & 111,97 \\
\hline 0.30 & 132.84 & 132,83 & 132,85 \\
\hline 0.50 & 142.54 & 142,54 & 142,55 \\
\hline 0.70 & 148.94 & 148,93 & 148,94 \\
\hline 0.90 & 153.71 & 153,71 & 153,72 \\
\hline 1.10 & 157.52 & 157,52 & 157,53 \\
\hline 1.30 & 160.70 & 160,70 & 160,71 \\
\hline 1.50 & 163.42 & 163,41 & 163,42 \\
\hline 1.70 & 165.80 & 165,79 & 165,80 \\
\hline 1.90 & 167.91 & 167,91 & 167,92 \\
\hline 2.10 & 169.81 & 169,81 & 169,82 \\
\hline 2.30 & 171.54 & 171,54 & 171,55 \\
\hline 2.50 & 173.12 & 173,12 & 173,13 \\
\hline
\end{tabular}

Tabel IV merupakan hasil perhitungan path loss menggunakan metode SUI dimana didapatkan nilai-nilai path loss dari BTS 1 - BTS 3 dari jarak 10 meter sampai dengan $2,5 \mathrm{~km}$.

3. Perhitungan Path Loss dengan Metode Cost-231

Contoh perhitungan path loss untuk Cost-231 Dimana

$$
\begin{array}{ll}
f & =946,2 \mathrm{MHz} \\
h_{b s} & =30 \text { meter } \\
h_{m s} & =1,5 \text { meter } \\
A 1 & =4,63+33,9 \log _{10}(f)-13,82 \log _{10}\left(h_{b t s}\right) \\
B & =44,9-6,55 \log _{10}\left(h_{b s}\right) \\
C & =0,8+h_{m s}\left(-0,7+1,1 \log _{10}(f)\right)-1_{z}, 56 \log _{10}(f) \\
D & \left.=5,4+2 \log _{10}(f / 28)\right)^{2}
\end{array}
$$

Penyelesaian

$$
\begin{aligned}
P_{1} & =A 1+B \log 10(d)-C-D \\
& =126,772+35,225 \log 10(1)-0,017838-10,074611 \\
& =81,45 d B
\end{aligned}
$$

Tabel V

Hasil perhitungan Path Loss menggunakan Cost-231

\begin{tabular}{|c|c|c|c|}
\hline \multirow{2}{*}{$\mathrm{d}(\mathrm{km})$} & \multicolumn{3}{|c|}{ COST-231 (dB) } \\
\cline { 2 - 4 } & $\begin{array}{c}\text { BTS 1 } \\
(946,2 \mathrm{MHz})\end{array}$ & $\begin{array}{c}\text { BTS 2 } \\
(945,8 \mathrm{MHz})\end{array}$ & $\begin{array}{c}\text { BTS 3 } \\
(946,8 \mathrm{MHz})\end{array}$ \\
\hline 0,10 & 81,45 & 81.45 & 81.46 \\
\hline 0.30 & 98,26 & 98.26 & 98.27 \\
\hline 0.50 & 106,08 & 106.07 & 106.08 \\
\hline 0.70 & 111,22 & 111.22 & 111.23 \\
\hline 0.90 & 115,07 & 115.06 & 115.08 \\
\hline 1.10 & 118,14 & 118.13 & 118.14 \\
\hline 1.30 & 120,69 & 120.69 & 120.70 \\
\hline 1.50 & 122,88 & 122.88 & 122.89 \\
\hline 1.70 & 124,80 & 124.79 & 124.80 \\
\hline 1.90 & 126,50 & 126.49 & 126.51 \\
\hline 2.10 & 128,03 & 128.02 & 128.04 \\
\hline 2.30 & 129,42 & 129.42 & 129.43 \\
\hline 2.50 & 130,70 & 130.69 & 130.70 \\
\hline
\end{tabular}

Tabel V merupakan hasil perhitungan path loss menggunakan metode cost-231, dimana didapatkan nilainilai path loss dari BTS 1 - BTS 3 dari jarak $0,1 \mathrm{~km}$ sampai dengan $2,5 \mathrm{~km}$.

Setelah menghitung path loss dari free space, SUI, dan cost-231 selanjutnya adalah menentukan data path loss jaringan GSM Telkomsel di kota Tarakan. Sebelumnya perlu diketahui dulu nilai-nilai EIRP dan $P_{r}$, nilai-nilai tersebut merupakan data sekunder yang diambil dari penelitian terdahulu [1]. Dimana data-data tersebut didapat dari PT. Telekomunikasi Selular Regional Kalimantan Cabang Tarakan.

Contoh hasil perhitungan path loss jaringan GSM Telkomsel di Tarakan.

$$
\text { Dimana } \quad \begin{array}{ll}
\text { EIRP } & =43 \\
P_{R} & =-43
\end{array}
$$


Penyelesaian :

$$
\begin{aligned}
P_{L} \quad & =E I R P-P_{R} \\
& =43-(-43) \\
& =86 d B
\end{aligned}
$$

Tabel VI

Hasil perhitungan Path Loss Jaringan GSM Telkomsel di Kota Tarakan

\begin{tabular}{|c|c|c|c|c|r|c|}
\hline $\begin{array}{c}\text { d(k } \\
\text { m) }\end{array}$ & $\begin{array}{l}\text { PT_B } \\
\text { TS1 }\end{array}$ & $\begin{array}{l}\text { PL_B } \\
\text { TS1 }\end{array}$ & $\begin{array}{l}\text { PT_B } \\
\text { TS2 }\end{array}$ & $\begin{array}{l}\text { PL_B } \\
\text { TS2 }\end{array}$ & $\begin{array}{c}\text { PT_B } \\
\text { TS3 }\end{array}$ & $\begin{array}{l}\text { PL_B } \\
\text { TS3 }\end{array}$ \\
\hline 0,1 & -43 & 86 & -41 & 84 & -45 & 88 \\
\hline 0,3 & -55 & 98 & -61 & 104 & -57 & 100 \\
\hline 0,5 & -59 & 102 & -65 & 108 & -67 & 110 \\
\hline 0,7 & -68 & 111 & -64 & 107 & -71 & 114 \\
\hline 0,9 & -67 & 110 & -68 & 111 & -73 & 116 \\
\hline 1,1 & -64 & 107 & -82 & 125 & -80 & 123 \\
\hline 1,3 & -68 & 111 & -83 & 126 & -77 & 120 \\
\hline 1,5 & -69 & 112 & -89 & 132 & -86 & 129 \\
\hline 1,7 & -76 & 119 & -91 & 134 & -94 & 137 \\
\hline 1,9 & -76 & 119 & -90 & 133 & -89 & 132 \\
\hline 2,1 & -83 & 126 & -89 & 132 & -88 & 131 \\
\hline 2,3 & -91 & 134 & -109 & 152 & -93 & 136 \\
\hline 2,5 & -104 & 147 & -106 & 149 & -96 & 139 \\
\hline 1,7 & -76 & 119 & -91 & 134 & -94 & 137 \\
\hline
\end{tabular}

Tabel VI menunjukan hasil pengukuran path loss pada jaringan GSM Telkomsel kota Tarakan. Pada tabel terdapat nilai $P_{r}$ yang didapat dari PT. Telekomunikasi Selular Regional Kalimantan Cabang Tarakan.mulai dari BTS 1-BTS 3 yang diukur dari jarak $0,1 \mathrm{~km}$ sampai dengan $2,5 \mathrm{~km}$.

\section{IV.KESIMPULAN}

Dari hasil penelitian yang telah dilakukan dapat disimpulkan sebagai berikut :

1. Dari hasil perhitungan path loss yang dilakukan dapat disimpulkan bahwa dari ketiga pemodelan yang dipakai yaitu free space, SUI, dan cost-231 ternyata pemodelan yang paling cocok digunakan di kota Tarakan diantara ketiga pemodelan tersebut adalah cost-231. Hal ini bisa dilihat pada table 4.6 hasil perhitungan RSME.

2. Pada hasil perhitungan yang telah dilakukan menggunakan metode free space, cost-231, dan SUI dapat diambil kesimpulan bahwa semakin besar jarak antara BTS dengan penerima, maka semakin besar path loss yang dihasilkan. Tetapi pada hasil pengukuran menggunakan data dari PT. Telekomunikasi cabang Tarakan menunjukkan nilai yang berbeda.

3. Hasil perhitungan juga menunjukkan bahwa semakin besar path loss yang dihasilkan maka kapasitas pengguna yang sedang melakukan komunikasi akan berkurang sedangkan pada hasil pengukuran menunjukkan nilai yang berbeda.

\section{UCAPAN TERIMA KASIH}

Terima kasih penulis ucapkan kepada segenap pihak yang secara langsung maupun tidak langsung telah berkontribusi baik terhadap proses penyusunan tulisan ini maupun dalam proses publikasinya. Terima kasih kepada para author yang naskahnya penulis jadikan sebagai referensi.

\section{REFERENSI}

[1] Eka Riskayadi, (2015), " Pemodelan Path Loss Dengan Menggunakan Perambatan Okumura-Hatta Untuk Jaringan GSM di Tarakan"

[2] COST 231 report, (1999), "Digital Mobile Radio towards Future Generation Systems".

[3] Lee J.S and Miller L.E, (1998), "CDMA system Engineering Handbook, Artech House".

[4] Lina Mubarokah, (2009), Pengukuran dan Perhitungan Path Loss Eksponen Untuk Cluster Residences, Central Business Distric (CBD) dan Perkantoran di Daerah Urban, ITS, Surabaya.

[5] Rekawt S. Hassan, T. A. Rahman, A. Y. Abdulrahman, (2014), "LTE Coverage Network Planning and Comparison with Different Propagation Models".

[6] Liang Guo, Jie Zhang and Carsten Maple, (2013), "Coverage and Capacity Calculations for $3 G$ Mobile Network Planning".

[7] Pratama Putra, K. (2014), "Analisis Performance Jaringan $2 g$ Global System For Mobile Comunication (Gsm) Frekuensi 900 Mhz Dan1800 Mhz Berdasarkan Data Drive Test di Pt. Telkomsel Padang". 